International Review of Research in Open and Distributed Learning

Volume 17, Number 1

January - 2016

\title{
An Empirical Study of Factors Affecting Mobile Wireless Technology Adoption for Promoting Interactive Lectures in Higher Education
}

Chin Lay Gan and Vimala Balakrishnan

University of Malaya, Malaysia

\begin{abstract}
Use of mobile technology is widespread, particularly among the younger generation. There is a huge potential for utilizing such technology in lecture classes with large numbers of students, serving as an interaction tool between the students and lecturers. The challenge is to identify significant adoption factors to ensure effective adoption of mobile technology to promote interactivity between students and lecturers. This paper aims to examine factors supporting the use of mobile wireless technology during lectures to promote interactivity between students and lecturers in Malaysia's higher education institutions. A survey involving higher education students enrolled in on-campus academic courses in Malaysia was conducted with a sample size of 302. Factor analysis results identified five factors: independent variables System Usefulness (SU), User System Perception (USP), User Uncertainty Avoidance (UUA), System and Information Quality (SIQ), and dependent variable Mobile Wireless Technology Adoption for Interactive Lectures (MWT_AIL). All independent variables are positively associated to MWT_AIL, with UUA and SIQ having higher levels of significance compared to SU and USP. Respondents were selected from higher learning institutions from urban areas in Malaysia. Therefore results obtained are not representative of the entire higher education landscape in Malaysia, and future studies are warranted to include higher learning institutions located in rural areas. It is hoped that findings from this study will serve as a catalyst for future studies to be conducted, particularly among higher education researchers seeking ways to utilize technology effectively to enhance the learning experiences of students.
\end{abstract}


Keywords: computer mediated communication; open learning; higher education; interactive lectures; mobile wireless technology

\section{Introduction}

It is customary for higher education lectures to have large numbers of students, whether in traditional face to face classes or online classes. To enhance students' learning experiences, initiatives must be taken to promote an open learning environment that encourages interactivity (Erickson \& Siau, 2003; Reeves, 2006). Interactivity occurs when students are able to actively participate and provide feedback, and receive prompt responses from their teachers or friends (Sabry \& Barker, 2009). However, time constraint makes it difficult for lecturers to encourage students to feedback or to address their queries (Dobson-Mitchell, 2011; Shen, Wang, Gao, Noval, \& Tang, 2009). Tesch, Coelho, and Drozdenko (2011) identified the most common reason for students' inattention is when they do not understand and lack opportunities to ask questions during lectures. Furthermore, students' who are shy or prone to anxiety rarely if at all interrupt ongoing lectures to seek further clarifications, and computing technology utilised as an interaction tool may benefit these students (Cotner, Fall, Wick, Walker, \& Baepler, 2008; Gan \& Balakrishnan, 2014; Stowell, Oldham, \& Bennett, 2010). Web 2.0 tools such as Twitter to gather students' feedback (Elavsky, Mislan, \& Elavsky, 2011), and classroom response systems (BlascoArcas, Buil, Hernandez-Ortega, \& Sese, 2013) are able to effectively improve students' participation (Hoekstra, 2008; Stowell \& Nelson, 2007).

Mobile technology has also provided much needed convenience for students to access learning materials, facilitate online group discussions (Lundin, Lymer, Holmquist, \& Brown, 2010), enabling them to copy notes at a faster rate using laptops or tablets, and easing collaboration outside the classrooms (Kay \& Lauricella, 2011). For instance, mobile applications such as Socrative provide lecturers with the means to conduct real-time assessments to gauge students' understanding, and generate reports of students' level of participation in online assessments and collaborative discussions. Classroom response systems ("Clickers") allow lecturers to field multiple-choice questions on the whiteboard or via a computer projector in the classrooms, and students are to answer each question using a handheld transmitter. The benefit of using Clickers is their ability to summarize results in chart forms such as a histogram, thus allowing lecturers to know the exact percentage of students who answered correctly versus those who answered incorrectly. Lecturers can also view names of students who answered correctly and incorrectly. Tools such as Socrative and Clickers promote interactivity by providing a platform for lecturers to gather students' responses not otherwise possible in classes with large number of students or students enrolled in online courses (Cobb, Heaney, Corcoran, \& Henderson-Begg, 2010; Trees \& Jackson, 2007). 
Students' academic achievements represent a key aspect of teaching effectiveness (Webster \& Hackley, 1997). Evidence suggests that using technology to facilitate interactions between students and lecturers does improve students' results (Mayer et al., 2009; Morling, McAuliffe, Cohen, \& DiLorenzo, 2008). Lectures that utilized computer systems that enable the students to attempt multiple choice questions and provide immediate results to their selected answers, coupled with further explanations from their lecturers, obtained better results in a retention and transfer test, suggesting that the use of such systems not only raises interactivity but also improve students' academic achievements (Campbell \& Mayer, 2009). Other benefits observed from using technology as a communication tool are improving students' attention, participation and engagement, enabling group discussions among students, and an overall improvement to the quality of learning (Kay \& LeSage, 2009; Wang, Shen, Novak, \& Pan, 2009).

However, the use of technology during lectures by students and lecturers has some drawbacks, for instance causing disruptions to lectures, loss of attention among students due to discreet exchanges of text messages and playing mobile games (Scornavacca, Huff, \& Marshall, 2009). Additionally, incorporating a form of text-based messaging system to allow students to send their queries using their mobile devices may result in lecturers not being able to respond promptly to an avalanche of students' queries (Kay \& LeSage, 2009). As such, lecturers may not possess favourable views of using technology for teaching purposes. However, with proper regulations and etiquette in place, students can be guided to use mobile technology responsibly (Gaer, 2011). Alzaza and Yaakub (2011), and Mahat, Ayub, and Luan (2012) investigated Malaysian higher education students' readiness to use mobile technology, and findings suggest that students possess sufficient knowledge and maturity to use such technology properly for learning purposes.

Storck and Sproull (1995) found little or no difference pertaining to students' academic results between face to face and online classes. Key factors contributing towards students' satisfaction with online classes are quality and timely interaction with their lecturers (Young \& Norgard, 2006). Elements of online classes, for instance pre-recorded instructional videos and selfassessments, foster independence among students and allow students to learn at their own pace. Though technology such as video conferencing and online chat forums provide avenues for students and lecturers to interact in real-time, the formality of such platforms and the inconveniences of arranging chat schedules often limit interactions (Marra \& Jonassen, 2001; Volery \& Lord, 2000). Therefore, opportunities exist to utilise mobile applications developed for educational environments to ease interactions among students and lecturers.

\section{Rationale of Study}

Large lecture classes with many students, rigid lecture hall seating arrangements, and online lecture classes cause difficulties for the students to ask questions when they face doubts or inability to understand the lecture subject (Cotner et. al., 2008; Dobson-Mitchell, 2011; Doran \& Golen, 1998). Studies on the use of technology across higher learning institutions suggest that 
using technology improves interactions between students and lecturers, and students' academic performance (d'Inverno, Davis, \& White, 2003; Halloran, 1995; Poirier \& Feldman, 2007; Rehman, Afzal, \& Kamran, 2013). Concise delivery of the subject content, coupled with active students' engagement and interactions, are deemed supportive of students' learning efforts (Roopa, Bagavad Geetha, Rani, \& Chacko, 2013; Sarwar, Razzaq, \& Saeed, 2014). Students demonstrated positive perceptions for lecture classes that encourage them to actively participate and interact (Chilwant, 2012; Rehman, Afzal, \& Kamran, 2013). However, as the results of these studies focused on using mobile applications designed for specific subjects, generalizability across the higher education spectrum are limited. It is therefore essential to investigate the students' overall perceptions regarding use of mobile technology to promote interactive lectures.

Literature on technology adoption studies of information systems, motivational, and cultural theories were reviewed to identify key adoption factors. Davis's (1989) Technology Acceptance Model's (TAM) perceived ease of use and usefulness as extrinsic factors are well supported across a wide range of studies, with recent studies pointing to the importance of intrinsic motivators such as enjoyment and self-efficacy (Giesbers, Rienties, Tempelaar, \& Gijselaers, 2013; Yoo, Han, \& Huang, 2012). One of the key phases of the system development life cycle is system design, and systems with high-quality functionalities were deemed pivotal for ensuring success of information systems adoption (DeLone \& McLean, 1992; Detlor, Hupfer, Ruhi, \& Zhao, 2013). Cultural influences are gaining recognition in the field of system acceptances studies, with uncertainty avoidance from national cultural dimension theory (Hofstede, Hofstede, \& Minkov, 2010) proving to be an important determinant of technology acceptance (Hwang \& Lee, 2012). The present study thus extends TAM's perceived ease of use and usefulness, and includes information quality, system quality, self-efficacy, enjoyment, and uncertainty avoidance to provide a holistic insight that incorporates not just extrinsic and intrinsic motivator factors, but also factors that represent system development and cultural influences.

Furthermore, it may be useful to investigate students' preferences toward lecture sizes and barriers preventing them from asking questions during lectures, and their effects on mobile technology adoption. In addition, investigation on whether existing use of mobile messaging applications by students translate to higher levels of mobile technology adoption to promote interactivity during lectures.

\section{Extrinsic Perceptions Toward Mobile Wireless Technology (MWT) - Ease of Use, Usefulness, Information Quality, System Quality}

TAM hypothesized that perceived usefulness and perceived ease of use impact user attitude and behavioural intention toward subsequent acceptance of information systems (Davis, 1989). Perceived usefulness is the degree to which one believes using an information system will improve productivity, whereas perceived ease of use is the degree to which one believes using an 
information system will require minimal cognitive effort (Davis, 1989). TAM has been adopted and replicated in areas of students' perceptions toward the incorporation of multimedia components (Saadé, Nebebe, \& Tan, 2007) and mobile learning (Chong, Chong, Ooi, \& Lin, 2011). Parveen and Sulaiman (2008) incorporated TAM, and included personal innovativeness and technological complexity as determinants of TAM's perceived ease of use and perceived usefulness. Their results revealed both personal innovativeness and technological complexity to positively correlate with TAM's perceived ease of use and usefulness as determinants of user intention.

Studies have acknowledged the importance of system design, and one of the models include the DeLone and McLean Information System success model (D\&M). In the D\&M model, the determinants that lead to intention to use and user satisfaction are information quality and system quality, which was later modified to include service quality (DeLone \& McLean, 1992). Studies based on D\&M model revealed both information and system quality to be important in determining user acceptance (Cheng, Liu, Song, \& Qian, 2008; Wixom \& Todd, 2005). A recent study researching consumers' acceptance of Internet Protocol (IP) services proposed an integrated acceptance model, whereby perceived quality of service and perceived content quality constructs were included (Shin, 2009). Findings discovered significant positive effects from perceived quality of content and system toward behavioural intention (Shin, 2009).

\section{Intrinsic MWT Adoption Factors}

Social Cognitive Theory (SCT) was proposed as an attempt to explain human behaviour by placing importance on self-efficacy as a direct determinant of a person's behaviour (Bandura, 1977, 2001). Self-efficacy is defined as an individual's personal confidence in one's skills to use and interact with an instructor using MWT during lectures (Bandura, 2001; Holden \& Rada, 2011; Pituch \& Lee, 2006; Venkatesh, 2000). Pituch and Lee (2006) examined system characteristics that promote the adoption of e-learning, and found system functionality, system interactivity, system response, self-efficacy and Internet experience to be important determinants to perceived usefulness and ease of use, which leads to e-learning acceptance. The effect of user anxiety towards new technology and security concerns can directly reduce user self-efficacy, and thus negatively affect user adoption decisions (Yeow, YenYuen, \& Tong, 2008). Holden and Rada (2011) further validated the importance of technology self-efficacy as having a positive influence on teachers' technology acceptance.

Other intrinsic motivations come purely from an individual's sense of enjoyment in performing a task, without the need for reinforcements (Scott, Farh, \& Podaskoff, 1988). Motivational theory was applied to study the influence of perceived usefulness (extrinsic) and enjoyment (intrinsic) on intentions to use computers in the workplace, and both factors were found to have a strong correlation towards technology usage intention (Davis, Bagozzi, \& Warshaw, 1992). Findings

from studies on online learning acceptance which combined TAM with intrinsic motivational 
factor (enjoyment) supported the integrated model predictive capability (Yi \& Hwang, 2003; Zhang, Zhao, \& Tan, 2008). Studies on online learning acceptance revealed intrinsic factor (i.e., enjoyment) to strongly impact user behavioural intention (Yi \& Hwang, 2003; Zhang et al., 2008). A study to determine factors that lead to youth's adoption of wireless technology extended TAM by including perceived safety, enjoyment and peer influence. All the variables were found to have positive influence on behavioural intentions to adopt wireless technology, which strongly supports the actual adoption (Kim, 2008).

Hofstede, Hofstede, and Minkov (2010) defined an individual's uncertainty avoidance as the degree of discomfort when dealing with uncertainties and ambiguities. Uncertainty can be described as the lack of predictability, of composition, and of information (Rogers, 2003). In the study of Lee, Garbarino, and Lerman (2007), the researchers examined how people from various countries differ in uncertainty avoidance and product uncertainty when using new products. Their findings revealed a significant relationship between product uncertainty and cultural uncertainty avoidance. Ayoun and Moreo (2008) examined the influence of uncertainty avoidance in hotel managers' strategy development and found uncertainty avoidance had little influence on managerial approach. The study indicated that uncertainty avoidance level varies because of the different cultural background of managers (Ayoun \& Moreo, 2008). The effect of uncertainty avoidance reduces when people are more experienced and younger (Lee et al., 2007). Rogers (2003) also added that technological innovation entails information, thus reducing the uncertainty of the cause and effect in problem solving. In a study of online banking responses to the culture of the society in which it operates, TAM and Hofstede's cultural dimensions, i.e. power distance, individualism, masculinity and uncertainty avoidance, were applied (Singer, Avery, \& Baradwaj, 2008). Results showed that culture has an important influence on online banking, and all four cultural dimensions influenced online bank websites' design (Singer et al., 2008). Another study on European e-government adoption found high levels of power distance and uncertainty avoidance to have negative impact on e-government acceptance (Aykut, 2009).

\section{MWT for Interactive Lectures}

Theory of Reasoned Action (TRA) was rooted in the social psychology field, advocating behavioural intention as a predictor of actual user behaviour (Fishbein \& Ajzen, 1975). TRA proposes user attitude and subjective norm as determinants of behavioural intention (Ajzen, 1991). Attitude is one's perception of the consequences of performing a set of behaviours, whereas subjective norm is the perceived social pressure regarding a person's decision to perform a set of behaviours (Ajzen, 1991). The effect of attitude and subjective norm toward determining behavioural intention were inconsistent. Shih and Fang's (2004, 2006) study on e-banking acceptance revealed subjective norm to be insignificant as a predictor of behavioural intention. However, subjective norm was significant as a predictor of behavioural intention in a study of consumer halal food choices (Lada, Tanakinjal, \& Amin, 2008), and teachers' acceptance of elearning (Yuen \& Ma, 2008). In another study on e-banking adoption, subjective norm 
significance was supported, though user attitude had a stronger impact on adoption intention (Rouibah, Thurasamy, \& Oh, 2009).

Likewise, behaviour is postulated as being determined by intention to use (Davis, Bagozzi, \& Warshaw, 1989; Venkatesh, Morris, Davis, \& Davis, 2003). In the present study, intention to use MWT for interactive lectures is defined as students and lecturers' commitment to use MWT during lectures in the future as a tool to increase interactivity between them during lectures. A key difference has been noted in the concept of interaction and interactivity. Interaction focuses on communication behaviours while interactivity allows user to experience a series of interactions via technological mediums (Sutton, 2001). In higher education, lecture classes are the principal avenue for students' and lecturers' interactions. In this study, interactive lectures are defined as active interactions between students and lecturers during lectures using MWT, i.e., students sending messages to the lecturer freely during or after lecture classes ended, and lecturers viewing students' messages and responding accordingly.

\section{Aims and Hypotheses}

The main aim of the study was to first identify factors supporting adoption of MWT to promote interactions between students and lecturers. Identifying the key adoption factors of MWT will provide higher education institutions in Malaysia a mechanism for MWT implementation as an interaction tool during lectures to overcome the shortcomings of large lecture classes and online classes. It is hypothesized that factors identified positively (independent variables) influence adoption of MWT for interactive lectures (dependent variable). In regards to respondents' use of mobile messaging applications (such as WhatsApp), it is predicted that respondents who frequently have chat classes daily using such applications will be positively associated with factors promoting MWT adoption for interactive lectures compared to those who rarely or don't use mobile messaging applications. Additionally, students that prefer smaller lecture size (less than 50 students) are expected to exhibit positive perceptions towards factors promoting MWT as an interactivity tool during large lecture classes, while those that prefer large lecture size or don't mind the lecture size to have lower positive perceptions. Finally, respondents who face communication barriers during lectures, such as poor language skills or not wanting to interrupt the lectures are predicted to be positively associated with the factors for MWT adoption for interactive lectures.

\section{Research Methods}

\section{Survey}

Pilot test were conducted where ten selected students were gathered in a room to complete the survey questions. No more than ten minutes was required to complete the survey by the students, 
and feedback was gathered to refine the questions. The final survey comprised of four main sections:

1. The first section consisted of six questions relating to respondents' gender, age, higher learning institutions and educational details. The questions did not identify the respondents' identity, thus ensuring respondents' anonymity.

2. The second section consisted of four questions relating to respondents' type of mobile devices currently owned, means of Internet access, use of mobile messaging applications, and use of mobile devices for learning purposes.

3. The third section consisted of two questions pertaining to respondents' preference on lecture size, and the main barriers encountered that hinder communication with their lecturers during lectures (six checklist options were provided including an "other(s)" option).

4. The last section consisted of five item statements for each of the constructs identified (usefulness, ease of use, self-efficacy, enjoyment, uncertainty avoidance, system quality, information quality, MWT adoption). Respondents can rate their level of agreement for each item statement using a 5 -point Likert scale $(1=$ "Strongly disagree", $3=$ "Neutral", and $5=$ "Strongly agree").

\section{Respondents}

A total of 304 on-campus Malaysian students of higher education participated in the study by completing an online survey. Two sets of survey data from respondents who failed to complete the online questionnaire were removed. Of the remaining 302 remaining respondents, the average age was 22 years old $\left(N_{\text {males }}=144, N_{\text {females }}=158\right)$. The highest number of respondents were undergraduates, totalling $208\left(N_{\text {science }}=118, N_{\text {non-science }}=90\right)$, followed by 67 diploma students $\left(N_{\text {science }}=35, N_{\text {non-science }}=32\right), 23$ postgraduates $\left(N_{\text {science }}=16, N_{\text {non-science }}=7\right)$, and four foundation level students $\left(\mathrm{N}_{\text {science }}=4, \mathrm{~N}_{\text {non-science }}=0\right)$. All respondents owned at least one mobile device $\left(N_{\text {smartphone }}=264, N_{\text {laptop }}=221, N_{\text {mobile phone }}=98, N_{\text {tablet }}=50, N_{\text {netbook }}=17, N_{\text {e-book reader }}=6\right)$. Out of 302 respondents, 15 of them do not use their mobile devices for learning purposes. In regards to Internet access using their mobile devices, $79.1 \%$ respondents were able to access the Internet via a cellular network, and $95.7 \%$ respondents were able to through a Wi-Fi connection ( $N_{\text {cecullar network }}$ $=239, N_{W i-F i}=289$ ). None of the respondents used MWT to interact with their lecturers during lectures.

\section{Data Collection Procedure}

Approval for the study's survey of students of higher learning institutions in the country was obtained from University Malaya Research Ethics Committee in February 2014. Respondents were then recruited via email invitations sent to students at selected higher education institutions located in urban areas, and data were collected for approximately four months from April until July 2014. The email contained a hyperlink which took the respondents to the online survey 
hosted by Google Drive. An introductory statement to inform respondents about the aim of the study and assurance of confidentiality of their personal details was displayed first. Upon successful completion of the survey, the survey data were then saved into an Excel worksheet and respondents were directed to the "thank you" page. Data were then transferred from the Excel worksheet into the IBM SPSS Statistics 21 software and organized for statistical analysis.

\section{Results}

\section{Factor Analysis}

Constructs identified from reviews of acceptance models and theories for examining adoption of MWT for interactive lectures, i.e., Usefulness (U), Ease of Use (EU), Self-Efficacy (SE), Enjoyment (E), Uncertainty Avoidance (UA), System Quality (SQ), Information Quality (IQ), and MWT Adoption for Interactive Lectures (MWT_AIL), have five research items all loaded for exploratory factor analysis. The Kaiser-Meyer-Olkin value is 0.946 , indicating that the sample size is adequate for factor analysis and Bartlett's test of sphericity result is significant $\left(x^{2}=\right.$ $8747.75, d f=528, p<0.001)$.

A maximum likelihood analysis with direct oblimin rotation revealed that the construct's research items loaded into five factors: independent variables System Usefulness (SU), User System Perception (USP), User Uncertainty Avoidance (UUA), and System and Information Quality (SIQ), and dependent variable MWT Adoption for Interactive Lectures (MWT_AIL). Research items from enjoyment, self-efficacy and ease of use loaded together, strongly suggesting that intrinsic motivations (enjoyment and self-efficacy) for technology adoption are tightly interrelated, and self-efficacy, i.e., users' self-confidence, is strongly related to their beliefs that using an information system will require minimal effort (ease of use).

Research items that fail to adequately measure the latent variables were removed from further empirical testing. Factor pattern coefficients for the five factors are presented in Table 1.

Table 1

Factor loads for exploratory factor analysis with direct oblimin rotation.

\begin{tabular}{lccccc}
\hline & SU & USP & UUA & SIQ & MWT_AIL \\
\hline U1 & .775 & .092 & -.060 & .045 & .008 \\
U2 & .799 & .081 & .004 & .067 & .005 \\
U3 & .732 & -.101 & .207 & -.042 & -.024 \\
U4 & .662 & .095 & -.002 & .149 & .022 \\
U5 & .693 & .196 & -.021 & -.009 & .061 \\
\hline EOU2 & .320 & .535 & -.005 & -.006 & .054
\end{tabular}




\begin{tabular}{|c|c|c|c|c|c|}
\hline EOU5 & .397 & .451 & -.078 & .185 & -.032 \\
\hline SE1 & .152 & .587 & -.098 & .247 & -.078 \\
\hline SE3 & .250 & .558 & -.065 & .180 & -.013 \\
\hline SE5 & .226 & .472 & -.069 & .293 & .022 \\
\hline E1 & .018 &. $\mathbf{8 1 7}$ & -.006 & .009 & .043 \\
\hline E2 & .072 & .621 & .139 & .098 & .025 \\
\hline E3 & .015 & .551 & .245 & -.051 & .067 \\
\hline $\mathrm{E}_{4}$ & .048 & .759 & .137 & -.028 & .016 \\
\hline E5 & .058 & .788 & .058 & .052 & -.015 \\
\hline UA2 & .056 & .013 & .417 & .258 & -.026 \\
\hline UA3 & .036 & .080 & .736 & .031 & .060 \\
\hline UA4 & .165 & .070 & .728 & .077 & .071 \\
\hline UA5 & .082 & .182 & .585 & .184 & .045 \\
\hline SQ2 & -.049 & -.002 & .106 & .495 & .035 \\
\hline SQ3 & -.063 & .191 & .222 & .473 & -.023 \\
\hline $\mathrm{SQ}_{4}$ & .102 & .186 & .203 & .419 & -.091 \\
\hline SQ5 & .005 & .316 & .150 & .418 & -.105 \\
\hline IQ1 & .062 & -.002 & .034 & .678 & .125 \\
\hline IQ2 & .117 & .058 & -.021 & .733 & -.019 \\
\hline IQ3 & .029 & -.127 & -.006 & .892 & .041 \\
\hline IQ4 & -.006 & .032 & -.006 & .905 & -.020 \\
\hline IQ5 & .121 & .148 & -.025 & .657 & -.011 \\
\hline MWT_AIL1 & .104 & -.125 & .075 & -.023 & .734 \\
\hline MWT_AIL 2 & .028 & -.073 & .052 & -.037 & .803 \\
\hline MWT_AIL 3 & -.061 & .005 & -.022 & .121 & .871 \\
\hline MWT_AIL 4 & -.029 & .129 & -.032 & .012 & .861 \\
\hline MWT_AIL 5 & -.053 & .115 & -.059 & -.005 & .921 \\
\hline
\end{tabular}

Note: Factor loadings $>.40$ are bold. $\mathrm{SU}=$ System Usefulness; USP = User System Perception; UUA = User Uncertainty Avoidance; SIQ = System and Information Quality; MWT_AIL = MWT Adoption for Interactive Lectures.

Based on the results of the factor analysis, reliability test was conducted to the factors and results are presented in Table 2. Cronbach's Alpha scores showed all factors displayed acceptable internal consistencies $(>0.70)$.

Table 2

Reliability analysis of each factors.

\begin{tabular}{lcccc}
\hline Factors & $\begin{array}{c}\text { Number } \\
\text { of Items }\end{array}$ & $\begin{array}{c}\text { Cronbach's } \\
\text { Alpha }\end{array}$ & Mean & $\begin{array}{c}\text { Standar } \\
\text { d Dev. }\end{array}$ \\
\hline 1. System Usefulness & 5 & 0.909 & 4.12 & 0.919 \\
2. User System Perception & 10 & 0.948 & 4.10 & 0.913
\end{tabular}




\begin{tabular}{llllc} 
3. User Uncertainty Avoidance & 4 & 0.869 & 3.58 & 0.967 \\
4. System and Information Quality & 9 & 0.921 & 3.80 & 0.844 \\
5. MWT Adoption for Interactive Lectures & 5 & 0.925 & 3.08 & 1.192 \\
\hline
\end{tabular}

The covariance between each independent variable (SU, USP, UUA, SIQ) and the dependent variable (MWT_AIL) were calculated using Pearson's correlation coefficient (two-tailed). Associations between the independent variables and dependent variable were positive. There was significant positive correlation between UUA and MWT_AIL $(r=.233, n=302, p<0.01)$, and between SIQ and MWT_AIL $(r=.149, n=302, p<0.01)$. On the other hand, SU $(r=.139, n=$ $302, p<0.05)$ and USP $(r=.145, n=302, p<0.05)$ exhibit lower positive correlation with MWT_AIL.

\section{Frequency of Daily Chat Sessions Using Mobile Messaging Applications}

In regards to how often respondents use mobile messaging applications such as WhatsApp (i.e., number of chat sessions per day), $58.3 \%$ use them more than ten times a day, $21.2 \%$ use them not more than five times a day, and $16.2 \%$ use them between six to ten times a day. The remaining $4.3 \%$ of respondents don't use mobile messaging applications. In order to investigate whether there are statistically significant differences between respondents' frequency of chat sessions daily using mobile messaging applications and each of the factors identified, a series of one-way analysis of variance (ANOVA) was performed.

There was no statistically significant difference between respondents' frequency of chat sessions daily and the System Usefulness (SU) factor $(F(3,296)=2.043, p=.108)$. The second ANOVA revealed a statistically significant difference between respondents' frequency of chat sessions daily and the User System Perception (USP) factor $(F(3,296)=5.497, p=.001)$. A Tukey post-hoc test revealed that the mean for USP was statistically different between respondents who use mobile messaging applications more than ten times a day $(4.2 \pm .76)$ and those who use them not more than five times a day $(3.9 \pm .76, p=.029)$, and respondents who doesn't use mobile messaging applications $(3.5 \pm .56, p=.012)$. There was a statistically significant difference between respondents' frequency of chat sessions daily and the User Uncertainty Avoidance (UUA) factor as determined by one-way ANOVA $(F(3,296)=5.011, p=.002)$. A Tukey post-hoc test revealed that respondents who do not use mobile messaging applications exhibited higher levels of uncertainties $(2.8 \pm .57)$ compared to respondents who use them between six to ten times a day $(3.5 \pm .71, p=.046)$, and respondents who use them more than ten times a day $(3.7 \pm .85, p=$. 002). There were no statistically significant differences between respondents' frequency of chat sessions daily and System and Information Quality (SIQ) factor $(F(3,296)=3.092, p=.027)$, and the MWT Adoption for Interactive Lectures (MWT_AIL) factor $(F(3,296)=.229, p=.876)$.

\section{Respondents' Lecture Size Preferences}


The mean scores of respondents who prefer smaller lectures with less than 50 students, large lectures with more than 50 students, and those who state that lecture size doesn't matter is presented in table 3 .

Table 3

Means (standard deviations) of factors among students who prefer small lectures, large lectures and those who doesn't mind the lecture size.

\begin{tabular}{llll}
\hline Factors & $\begin{array}{l}\text { Prefer small lecture size } \\
(n=214,70.9 \%)\end{array}$ & $\begin{array}{l}\text { Prefer large lecture size } \\
(n=20,6.6 \%)\end{array}$ & $\begin{array}{l}\text { Doesn't mind lecture size } \\
(n=68,22.5 \%)\end{array}$ \\
\hline SU & $4.12(.77)$ & $3.75(.98)$ & $4.23(.75)$ \\
USP & $4.12(.76)$ & $3.80(.69)$ & $4.12(.75)$ \\
UUA & $3.58(.83)$ & $3.39(.80)$ & $3.63(.81)$ \\
SIQ & $3.80(.66)$ & $3.58(.64)$ & $3.85(.65)$ \\
MWT_AIL & $3.13(1.09)$ & $3.16(1.10)$ & $3.22(1.15)$ \\
\hline
\end{tabular}

Note $:$ SU = System Usefulness; USP = User System Perception; UUA = User Uncertainty Avoidance; SIQ = System and Information Quality; MWT_AIL = MWT Adoption for Interactive Lectures.

In order to investigate whether preference towards lecture sizes influences their perceptions on the use of MWT to promote interactivity during lectures, one-way multivariate analysis of variance (MANOVA) was performed between the factors SU, USP, UUA, SIQ and MWT_AIL, with students' lecture size preferences. No significant multivariate effects were found between the subjects: $F(10,590)=.947, p=.490$; Wilk's $\quad=0.969$, partial $2=.016$.

\section{Communication Barriers During Lectures}

Respondents were asked to provide reason(s) preventing them from communicating with their lecturers during lectures when they do not understand subject content. Out of 302 respondents, 271 provided reason(s) preventing them from asking their lecturers (31 respondents stated that they do not face any problems of communication during lectures), with a total of 580 total responses. The most cited reasons were reluctance to interrupt the lecture ( $n=124,21.4 \%$ ), followed by having no confidence $(n=119,20.5 \%)$ and shyness $(n=107,18.5 \%)$. These were followed by poor language skills ( $n=89,15.3 \%$ ), afraid of sounding silly ( $n=80,13.8 \%)$ and lack of opportunity or time to ask questions during lectures $(n=61,10.5 \%)$. The covariance between communication barriers encountered during lectures and factors for determining MWT adoption for interactive lectures were calculated using Pearson correlation coefficient (two-tailed). Table 4 present the results, and significant correlations are indicated.

Table 4

Correlations between communication barriers during lectures and factors of $M W T$ AIL

Communication Barriers

Factors of MWT_AIL 


\begin{tabular}{lllll}
\hline & SU & USP & UUA & SIQ \\
\hline Not confident to ask questions in class. & .097 & .166 & $.121^{*}$ & .170 \\
Shy to ask questions in class. & .185 & $.206^{*}$ & $.286^{* *}$ & $.307^{* *}$ \\
Afraid of sounding silly. & -.011 & .061 & $.233^{*}$ & .123 \\
Poor language skills. & .204 & $.228^{*}$ & $.307^{* *}$ & $.324^{* *}$ \\
Did not want to interrupt the lecture or lecturer. & .114 & $.226^{*}$ & $.300^{* *}$ & $.236^{* *}$ \\
No opportunity or time to ask questions. & $.298^{*}$ & .217 & $.273^{*}$ & .165 \\
\hline
\end{tabular}

Note $: \mathrm{SU}=$ System Usefulness; USP = User System Perception; UUA = User Uncertainty Avoidance; SIQ = System and Information Quality; MWT_AIL = MWT Adoption for Interactive Lectures.

${ }^{*} \mathrm{p}<.05$ (two-tailed)

** $\mathrm{p}<.01$ (two-tailed)

\section{Discussion}

The current study aimed to identify crucial factors for determining MWT adoption for interactive lectures, focusing on higher education students in Malaysia. Based on reviews of literature on technology acceptance models and theories, key constructs deemed essential were identified. An online survey was conducted to elicit perceptions of MWT adoption to facilitate interaction between students and lecturers. Results from factor analysis using maximum likelihood analyses with direct oblimin rotation produced five factors: independent variables System Usefulness (SU), User System Perception (USP), User Uncertainty Avoidance (UUA), System and Information Quality (SIQ), and dependent variable MWT Adoption for Interactive Lectures (MWT_AIL). Items from system quality and information quality loaded together, with the resulting factor named SIQ, suggesting that distinctions between system quality and information quality may no longer be pivotal for mobile applications. Interestingly, ease of use, enjoyment and self-efficacy loaded together, with the resulting factor named USP. This affirms the significance of user beliefs or perceptions as an important technology adoption predictor (Park, Nam, \& Cha, 2012; Shroff, Deneen, \& Ng (2012).

In regards to the hypotheses formulated, the predictions that factors SU, USP, UUA and SIQ positively influence MWT_AIL were supported, with UUA and SIQ having higher levels of significance compared to SU and USP. The importance of usefulness (extrinsic factor), ease of use, and intrinsic factors conceptualized as enjoyment and self-efficacy has been consistently validated in many studies (Calisir, Altin Gumussoy, Bayraktaroglu, \& Karaali, 2014; PadillaMeléndez, del Aguila-Obra, \& Garrido-Moreno, 2013; Tarhini, Hone, \& Liu 2014). This may reflect a shift in the mind-set of higher education students adept with using Web 2.o tools and mobile technology, indicative of confidence in their computing expertise. For instance, the variety and complexities of functionalities in Facebook does not prevent many from using it, and Facebook remains the most popular social media platform (Duggan, Ellison, Lampe, Lenhart, \& 
Madden, 2015). This may be reflective of the quality and variety of services offered by Facebook, and that it provides instant gratification and enjoyment for its user.

Though findings from literature have consistently emphasize the importance of both intrinsic and extrinsic factors, the quality of mobile applications remains vital. Development of information systems such as an enterprise resource planning and decision support systems focuses greatly on the system analysis and design phases, an indication of the importance of system and information quality as predictor of acceptance (Olson \& Staley, 2012; Van Valkenhoef, Tervonen, Zwinkels, De Brock, \& Hillege, 2013). System and information qualities, such as reliability, flexibility, timeliness, input and output accuracy, and pleasing interface design are therefore essential. With the findings affirming system and information quality as a strong predictor of mobile technology acceptance, proper development methodology for mobile applications is therefore pivotal to aid mobile application developers in understanding user requirements.

Inclusion of uncertainty avoidance was driven by the gaining recognition of the influence of culture in technology acceptance. UUA's having the strongest significance strengthens the vital role of cultural dimensions in the field of technology acceptance, as supported by previous studies by Ayoun and Moreo (2008) and Aykut (2009). A recent study by Matusitz and Musambira (2013) proved that lower levels of uncertainty avoidance positively correlated to higher acceptance of cell phone subscriptions and internet use. Evidence was found to demonstrate uncertainty avoidance influencing consumer trust in online purchasing decision (Hwang \& Lee, 2012). Though SU and USP positively associated with MWT adoption intention, its lower significance contradicts the findings of Gao, Moe, and Krogstie (2010) and Holden and Rada (2011) where ease of use and self-efficacy have strong positive significance. Differences in the level of significance may be attributed to Gao et al.'s (2010) qualitative study involving less than 30 university students, and Holden and Rada's (2011) study focusing on the perspective of secondary school teachers.

In regards to the prediction that respondents who use mobile messaging applications frequently for chat sessions will exhibit stronger positive correlations with the factors identified compared to respondents who rarely or don't use such applications, results were varied. First, no statistical significant difference was found between respondents' frequency of chat sessions daily to SU, SIQ and MWT_AIL. Secondly, higher levels of associations were revealed for groups of respondents who uses such applications more than ten times a day compared to those that uses less than five times daily for USP. Lastly, respondents who use such mobile applications at least six times daily have stronger positive associations to UUA (i.e. lower levels of uncertainty avoidance) compared to those that do not use such applications. However, only $4.3 \%$ of respondents does not use mobile messaging applications, thus rendering the results inconclusive. Clearly this contradicts the supposition that respondents who are already familiar with existing mobile applications will exhibit higher acceptance level of MWT as an interactive tool during lectures. 
Differences of lecture size preferences among three groups of respondents, i.e., those that prefer small lecture size, those that prefer large lecture size, and those who are neutral, revealed no significant differences with the factors identified. However, an analysis of the mean values of factors SU, USP, UUA and SIQ revealed higher means for groups that prefer small lectures and groups that are indifferent about lecture size compared to the group that prefer large lecture size. Mean values of MWT_AIL generally are the same for each group. The results obtained are plausible as preference for smaller lectures may be attributed to limitations that large lecture sessions cause. As students in higher education generally do not have a say in determining the maximum lecture size capacity, students who prefer smaller lecture size will exhibit higher positive inclination toward the use of MWT to facilitate interactions during lectures based on the mean scores. The means for MWT_AIL however don't reveal differences between these groups, and suggests that unfamiliarity with the use of any form of technology during lectures to facilitate interaction with their lecturers may be an influencing component. Therefore, the hypothesis that preference for smaller lecture size translates to higher adoption of MWT as an interaction tool during large lectures is inconclusive.

In regards to the prediction that respondents who face communication barriers during lectures will have positive associations with each of the independent factors for MWT_AIL, results are varied. Barriers of shyness, poor language skill, and not wanting to interrupt lectures revealed positive associations of USP, UUA and SIQ towards MWT_AIL. Not having the opportunity or time constraint during lectures revealed significant correlation for SU and UUA towards MWT_AIL. Respondents who cite not having the confidence or afraid of sounding silly revealed only low positive associations for UUA towards MWT_AIL. Not possessing confidence or fear of sounding silly are attributes of insecurity or low self-esteem (Hermans, ter Laak, \& Maes, 1972; Stein, 2010), and therefore may explain why the use of MWT may not make any difference.

\section{Conclusion}

The study focused on Malaysian students from higher learning institutions located in urban areas to identify important factors of MWT to promote interactivity during lectures. Results from factor analysis loaded items from system quality and information quality into a single factor, indicative of the insignificance of differentiating information quality and system quality in the study of mobile technology acceptances in higher education. Items from ease of use, enjoyment, and self-efficacy were grouped together in factor analysis, representing user perceptions or beliefs. This differs from previous studies of technology acceptances, and reflects a simplicity approach or mind-set among youths towards mobile applications, suggesting that confidence, ease of use and ultimately enjoyment in using mobile applications are tightly correlated as opposed to distinct entities. This reflects the importance of having clear and easy to understand instructions in mobile applications designed for learning purposes, to ensure that minimal cognitive efforts were required and thus improving self-efficacy and enjoyment. 
The findings also point to the growing influence of cultural factors, and the importance of system and analysis efforts as predictors of successful mobile technology adoption among students of higher education. Therefore, understanding user requirements in the development of mobile applications, coupled with a user-centred approach may reduce levels of uncertainty avoidance or hesitation, and therefore increase students' willingness to adopt new mobile technology to support their learning activities. To summarize, the hypotheses that the factors identified (independent variables) positively influence adoption of MWT for interactive lectures (dependent variable) were supported, with uncertainty avoidance and system and information quality emerging as stronger predictors of MWT adoption.

The assumptions that students who are already familiar and using mobile messaging applications in their daily life will readily use applications designed for enabling them to send questions to their lecturers using mobile devices during lectures are not substantiated. While significant differences have been found between groups who uses mobile messaging applications, results suggest that user perceptions and their level of uncertainty are pivotal factors. As no previous research was found to study the association between the use of mobile applications and MWT adoption, this is an area where further research is justified. Differences in terms of lecture size preferences of the respondents does not suggest significant effects on use of MWT for interactive lectures. However, the higher means of factors SU, USP, UUA and SIQ associated with those who prefer smaller lecture size and those who don't mind the lecture size is noteworthy and merits further in-depth research. Respondents with issues of low self-esteem, i.e., lack of confidence or afraid of sounding silly in front of their friends, revealed almost no associations towards MWT_AIL except for UUA. Unfortunately, an in-depth analysis of the specific causes underlying this finding is not possible within the scope of this study and deserves further research, particular on how students' positive and negative traits influence their decision to adopt MWT to increase interactivity during lectures.

Findings from this study underline the educational potential of MWT to promote interactive lectures, thereby enriching the learning process of students in the classroom or online classes. Quality of mobile application design and integration of useful features that are easy and fun to use are essential to instil user confidence and reduce uncertainties. It is hoped that the results in this study will serve as the platform for further research into the area of mobile technology, particularly in areas of students' learning engagement, satisfaction, and knowledge retention. Taken together, the factors identified put forth direct associations towards MWT adoption intention. Future work of interest will involve further statistical analysis, namely confirmatory factor analysis and structural equation modelling. Another area of interest is the effect of students' personalities in the study of technology behavioural intention, which holds much promise due to the dearth of research done in this area. Comparative studies in terms of gender or sciences versus non-sciences disciplines may also produce critical insights. 


\section{Acknowledgement}

The authors wish to extend their gratitude to University of Malaya (RPo28A-14AET) for supporting this study.

\section{References}

Ajzen, I. (1991). The theory of planned behavior. Organizational behavior and human decision processes, 5o(2), 179-211.

Alzaza, N. S., \& Yaakub, A. R. (2011). Students' awareness and requirements of mobile learning services in the higher education environment. American Journal of Economics and Business Administration, 3(1), 95-100.

Aykut, A. (2009). Cross-cultural analysis of european e-government adoption. World Applied Sciences Journal, 7(9), 1124-1130.

Ayoun, B. M., \& Moreo, P. J. (2008). The influence of the cultural dimension of uncertainty avoidance on business strategy development: A cross-national study of hotel managers. International Journal of Hospitality Management, 27(1), 65-75.

Bandura, A. (1977). Self-efficacy: Toward a unifying theory of behavioral change. Psychological Review, 84(2), 191-215.

Bandura, A. (2001). Social cognitive theory: An agentic perspective. Annual Review of Psychology, 52, 1-26.

Blasco-Arcas, L., Buil, I., Hernandez-Ortega, B., \& Sese, F. J. (2013). Using clickers in class. The role of interactivity, active collaborative learning and engagement in learning performance. Computers \& Education, 62, 102-110.

Campbell, J., \& Mayer, R. E. (2009). Questioning as an instructional method: Does it affect learning from lectures? Applied Cognitive Psychology, 23(6), 747-759.

Calisir, F., Altin Gumussoy, C., Bayraktaroglu, A. E., \& Karaali, D. (2014). Predicting the Intention to Use a Web- Based Learning System: Perceived Content Quality, Anxiety, Perceived System Quality, Image, and the Technology Acceptance Model. Human Factors and Ergonomics in Manufacturing \& Service Industries, 24(5), 515-531. 
Cheng, D., Liu, G, Song, Y. F., \& Qian, C. (2008). Adoption of Internet banking: An integrated model. Paper presented at the 4th International Conference on Wireless Communications, Networking and Mobile Computing (WICOM 'o8), Dalian. Conference Publications.

Chilwant, K. S. (2012). Comparison of two teaching methods, structured interactive lectures and conventional lectures. Biomedical Research, 23(3), 363-366.

Chong, J. L., Chong, A. Y. L., Ooi, K. B., \& Lin, B. (2011). An empirical analysis of the adoption of m-learning in Malaysia. International Journal of Mobile Communications, 9(1), 1-18.

Cobb, S., Heaney, R., Corcoran, O., \& Henderson-Begg, S. (2010). Using mobile phones to increase classroom interaction. Journal of Educational Multimedia and Hypermedia, 19(2), 147-157.

Cotner, S. H., Fall, B. A., Wick, S. M., Walker, J. D., \& Baepler, P. M. (2008). Rapid feedback assessment methods: Can we improve engagement and preparation for exams in largeenrollment courses?. Journal of Science Education and Technology, 17(5), 437-443.

d'Inverno, R., Davis, H., \& White, S. (2003). Using a personal response system for promoting student interaction. Teaching Mathematics Applications, 22(4), 163-169.

Davis, F. D. (1989). Perceived usefulness, perceived ease of use, and user acceptance of information technology. MIS Quarterly, 13(3), 319-340.

Davis, F. D., Bagozzi, R. P., \& Warshaw, P. R. (1989). User acceptance of computer technology: A comparison of two theoretical models. Management Science, 35(8), 982-1003.

Davis, F. D., Bagozzi, R. P., \& Warshaw, P. R. (1992). Extrinsic and intrinsic motivation to use computers in the workplace. Journal of Applied Social Psychology, 22(14), 1111-1132. doi: 10.1111/j.1559-1816.1992.tboo945.x

DeLone, W. H., \& McLean, E. R. (1992). Information systems success: The quest for the dependent variable. Information systems research, 3(1), 60-95.

Detlor, B., Hupfer, M. E., Ruhi, U., \& Zhao, L. (2013). Information quality and community municipal portal use. Government Information Quarterly, 3o(1), 23-32.

Dobson-Mitchell, S. (2011). Are big classes really a problem? Retrieved April 10, 2013, from http://oncampus.macleans.ca/education/2011/12/16/are-big-classes-really-a-problem/ 
Doran, M. S., \& Golen, S. (1998). Identifying communication barriers to learning in large group accounting instruction. Journal of Education for Business, 73(4), 221-224.

Duggan, M., Ellison, N.B., Lampe, C., Lenhart, A., \& Madden, M. (2015, January 9). Social media update 2014. Pew Research Center. Retrieved from http://www.pewinternet.org/2015/o1/o9/social-media-update-2014

Elavsky, C. M., Mislan, C., \& Elavsky, S. (2011). When talking less is more: exploring outcomes of Twitter usage in the large- lecture hall. Learning, Media and Technology, 36(3), 215-233.

Erickson, J., \& Siau, K. (2003). E-ducation. Communications of the ACM, 46(9), 134-140.

Fishbein, M., \& Ajzen, I. (1975). Belief, attitude, intention, and behavior: An introduction to theory and research. Reading, MA: Addison-Wesley.

Gaer, S. (2011). Cell Phones in the Classroom? Yes! Adult Basic Education and Literacy Journal, 5(3), 176-180.

Gan, C. L., \& Balakrishnan, V. (2014). Determinants of mobile wireless technology for promoting interactivity in lecture sessions: an empirical analysis. Journal of Computing in Higher Education, 26(2), 159-181.

Gao, S., Moe, S. P., \& Krogstie, J. (2010, 13-15 June). An empirical test of the mobile services acceptance model. Paper presented at the 2010 Ninth Global Mobility Roundtable.

Giesbers, B., Rienties, B., Tempelaar, D., \& Gijselaers, W. (2013). Investigating the relations between motivation, tool use, participation, and performance in an e-learning course using web-videoconferencing. Computers in Human Behavior, 29(1), 285-292.

Halloran, L. (1995). A comparison of two methods of teaching: computer managed instruction and keypad questions versus traditional classroom lecture. Computers in Nursing, 13(6), 285-288.

Hermans, H. J., ter Laak, J. J., \& Maes, P. C. (1972). Achievement motivation and fear of failure in family and school. Developmental Psychology, 6(3), 520.

Hoekstra, A. (2008). Vibrant student voices: Exploring effects of the use of clickers in large college courses. Learning, Media and Technology, 33(4), 329-341. 
Hofstede, G., Hofstede, G. J., \& Minkov, M. (2010). Cultures and Organizations: Software of the Mind (3rd ed.): New York: McGraw-Hill USA.

Holden, H., \& Rada, R. (2011). Understanding the influence of perceived usability and technology self-efficacy on teachers' technology acceptance. Journal of Research on Technology in Education, 43(4), 343-367.

Hwang, Y., \& Lee, K. C. (2012). Investigating the moderating role of uncertainty avoidance cultural values on multidimensional online trust. Information \& management, 49(3), 171-176.

Kay, R. H., \& Lauricella, S. (2011). Exploring the benefits and challenges of using laptop computers in higher education classrooms: A formative analysis. Canadian Journal of Learning and Technology, 37(1), 1-18.

Kay, R. H., \& LeSage, A. (2009). Examining the benefits and challenges of using audience response systems: A review of the literature. Computers \& Education, 53(3), 819-827.

Kim, S. (2008). Appropriation of wireless technology: Direct impacting factors on the youth `s adoption intention and usage of the wireless application protocol phone. Information Technology Journal, 7(8), 1116-1124.

Lada, S., Tanakinjal, G. H., \& Amin, H. (2008). Predicting intention to choose halal products using theory of reasoned action. International Journal of Islamic and Middle Eastern Finance and Management, 2(1), 66 - 76.

Lee, Julie Anne, Garbarino, Ellen, \& Lerman, Dawn. (2007). How cultural differences in uncertainty avoidance affect product perceptions. International Marketing Review, 24(3), 330-349.

Lundin, J., Lymer, G., Holmquist, L. E., \& Brown, B. (2010). Integrating students' mobile technology in higher education. International Journal of Mobile Learning and Organisation, 4(1), 1-14.

Mahat, J., Ayub, A. F. M., \& Luan, S. (2012). An Assessment of Students' Mobile Self-Efficacy, Readiness and Personal Innovativeness towards Mobile Learning in Higher Education in Malaysia. Procedia-Social and Behavioral Sciences, 64, 284-290.

Marra, R. M., \& Jonassen, D. H. (2001). Limitations of online courses for supporting constructive learning. Quarterly Review of Distance Education, 2(4), 303-317. 
Matusitz, J., \& Musambira, G. (2013). Power distance, uncertainty avoidance, and technology: analyzing Hofstede's dimensions and human development indicators. Journal of Technology in Human Services, 31(1), 42-60.

Mayer, R. E., Stull, A., DeLeeuw, K., Almeroth, K., Bimber, B., Chun, D., . . Zhang, H. (2009). Clickers in college classrooms: Fostering learning with questioning methods in large lecture classes. Contemporary Educational Psychology, 34(1), 51-57.

Morling, B., McAuliffe, M., Cohen, L., \& DiLorenzo, T. M. (2008). Efficacy of personal response systems ("clickers") in large, introductory psychology classes. Teaching of Psychology, 35(1), 45-50.

Olson, D. L., \& Staley, J. (2012). Case study of open-source enterprise resource planning implementation in a small business. Enterprise Information Systems, 6(1), 79-94.

Padilla-Meléndez, A., del Aguila-Obra, A. R., \& Garrido-Moreno, A. (2013). Perceived playfulness, gender differences and technology acceptance model in a blended learning scenario. Computers \& Education, 63, 306-317.

Park, S. Y., Nam, M. W., \& Cha, S. B. (2012). University students' behavioral intention to use mobile learning: Evaluating the technology acceptance model. British Journal of Educational Technology, 43(4), 592-605.

Parveen, F., \& Sulaiman, A. (2008). Technology complexity, personal innovativeness and intention to use wireless Internet using mobile devices in Malaysia. International Review of Business Research Papers, 4(5), 1-10.

Pituch, K. A., \& Lee, Y. K. (2006). The influence of system characteristics on e-learning use. Computers \& Education, 47(2), 222-244.

Poirier, C. R., \& Feldman, R. S. (2007). Promoting active learning using individual response technology in large introductory psychology classes. Teaching of Psychology, 34(3), 194196.

Reeves, T. C. (2006). How do you know they are learning? The importance of alignment in higher education. International Journal of Learning Technology, 2(4), 294-309.

Rehman, R., Afzal, K., \& Kamran, A. (2013). Interactive lectures: a perspective of students and lecturers. Journal of Postgraduate Medical Institute, 27(2), 152-156.

Rogers, E. M. (2003). Diffusion of innovations (5th ed.). New York: Free Press. 
Roopa, S., Bagavad Geetha, M., Rani, A., \& Chacko, T. (2013). What Type of Lectures Students Want? A Reaction Evaluation of Dental Students. Journal of clinical and diagnostic research: $J C D R, 7(10), 2244-2246$.

Rouibah, K., Thurasamy, R., \& Oh, S. M. (2009). User acceptance of Internet banking in Malaysia: Test of three competing models. International Journal of E-Adoption, 1(1-19).

Saadé, R. G. , Nebebe, F. , \& Tan, W. (2007). Viability of the "technology acceptance model" in multimedia learning environments: A comparative study. Interdisciplinary Journal of Knowledge and Learning Objects, 3, 175-184.

Sabry, K., \& Barker, J. (2009). Dynamic interactive learning systems. Innovations in Education and Teaching International, 46(2), 185-197.

Sarwar, S., Razzaq, Z., \& Saeed, I. (2014). Evaluation of interactive lectures: an innovative approach employed in a hybrid teaching system. Pak J Physiol, 10, 3-4.

Scornavacca, E., Huff, S., \& Marshall, S. (2009). Mobile phones in the classroom: if you can't beat them, join them. Communications of the ACM, 52(4), 142-146.

Scott, W. E., Farh, J., \& Podaskoff, P. M. (1988). The effects of "intrinsic" and "extrinsic" reinforcement contingencies on task behavior. Organizational Behavior and Human Decision Processes, 41(3), 405-425.

Shen, R., Wang, M., Gao, W., Noval, D., \& Tang, L. (2009). Mobile learning in a large blended computer science classroom: System function, pedagogies, and their impact on learning. IEEE TRANSACTIONS ON EDUCATION, 52(4), 538-546.

Shih, Y., \& Fang, K. (2004). The use of a decomposed theory of planned behavior to study Internet banking in Taiwan. Internet Research, 14(3), 213-223.

Shih, Y., \& Fang, K. (2006). Effects of network quality attributes on customer adoption intentions of Internet banking. Total Quality Management \& Business Excellence, 17(1), 61-77.

Shin, D. H. (2009). Determinants of customer acceptance of multi-service network: An implication for IP-based technologies. Information \& Management, 46(1), 16-22.

Shroff, R. H., Deneen, C. D., \& Ng, E. M. (2011). Analysis of the technology acceptance model in examining students' behavioural intention to use an e-portfolio system. Australasian Journal of Educational Technology, 27(4), 600-618. 
Singer, D., Avery, A., \& Baradwaj, B. (2008). Management innovation and cultural adaptivity in international online banking. Management Research News, 31(4), 258-272.

Stein, G. (2010). Signs of insecurity behavior. Retrieved August 21, 2014 from http://drgeraldstein.wordpress.com/2010/o7/15/signs-of-insecurity-behavior-thatreveals-a-lack-of-confidence/

Storck, J., \& Sproull, L. (1995). Through a Glass Darkly What Do People Learn in Videoconferences?. Human Communication Research, 22(2), 197-219.

Stowell, J. R., \& Nelson, J. M. (2007). Benefits of electronic audience response systems on student participation, learning, and emotion. Teaching of psychology, 34(4), 253-258.

Stowell, J. R., Oldham, T., \& Bennett, D. (2010). Using student response systems (“Clickers”) to combat conformity and shyness. Teaching of Psychology, 37(2), 135-140. doi: 10.1080/00986281003626631

Sutton, L. A. (2001). The principle of vicarious interaction in computer-mediated communications. International Journal of Educational Telecommunications, 7(3), 223242.

Tarhini, A., Hone, K., \& Liu, X. (2014). Measuring the Moderating Effect of Gender and Age on ELearning Acceptance in England: A Structural Equation Modeling Approach for an Extended Technology Acceptance Model. Journal of Educational Computing Research, 51(2), 163-184.

Tesch, F., Coelho, D., \& Drozdenko, R. (2011). The Relative Potency of Classroom Distracters on Student Concentration: We Have Met the Enemy and He Is Us*. Paper presented at the ASBBS Annual Conference, Las Vegas.

Trees, A. R., \& Jackson, M. H. (2007). The learning environment in clicker classrooms: student processes of learning and involvement in large university- level courses using student response systems. Learning, Media and Technology, 32(1), 21-40.

Van Valkenhoef, G., Tervonen, T., Zwinkels, T., De Brock, B., \& Hillege, H. (2013). ADDIS: a decision support system for evidence-based medicine. Decision Support Systems, 55(2), 459-475. 
Venkatesh, V. (2000). Determinants of perceived ease of use: integrating control, intrinsic motivation, and emotion into the technology acceptance model. Information Systems Research, 11(4), 342-365.

Venkatesh, V., Morris, M. G., Davis, G. B., \& Davis, F. D. (2003). User acceptance of information technology: Toward a unified view. MIS Quarterly, 27(3), 425-478.

Volery, T., \& Lord, D. (2000). Critical success factors in online education. International Journal of Educational Management, 14(5), 216-223.

Wang, M., Shen, R., Novak, D., \& Pan, X. (2009). The impact of mobile learning on students' learning behaviours and performance: Report from a large blended classroom. British Journal of Educational Technology, 40(4), 673-695.

Webster, J., \& Hackley, P. (1997). Teaching effectiveness in technology-mediated distance learning. Academy of management journal, 4O(6), 1282-1309.

Wixom, B. H., \& Todd, P. A. (2005). A theoretical integration of user satisfaction and technology acceptance. Information Systems Research, 16(1), 85-102.

Yeow, P. H. P., YenYuen, Y., \& Tong, D. Y. K. (2008). User acceptance of online banking service in Australia. Communications of the IBIMA, 1, 191-197.

Yi, M. Y., \& Hwang, Y. (2003). Predicting the use of web-based information systems: self-efficacy, enjoyment, learning goal orientation, and the technology acceptance model. International Journal of Human-Computer Studies, 59(4), 431-449.

Yoo, S. J., Han, S. H., \& Huang, W. (2012). The roles of intrinsic motivators and extrinsic motivators in promoting e-learning in the workplace: A case from South Korea. Computers in Human Behavior, 28(3), 942-950.

Young, A., \& Norgard, C. (2006). Assessing the quality of online courses from the students' perspective. The Internet and Higher Education, 9(2), 107-115.

Yuen, A. H. K., \& Ma, W. W. K. (2008). Exploring teacher acceptance of e-learning technology. Asia-Pacific Journal of Teacher Education, 36(3), 229-243.

Zhang, S., Zhao, J., \& Tan, W. (2008). Extending TAM for online learning systems: An intrinsic motivation perspective. Tsinghua Science and Technology, 13(3), 312-317. 


\section{Appendix: Survey items}

\section{Usefulness}

1. MWT provides convenience for me to access learning materials anytime, anywhere.

2. MWT allows me to communicate with my classmates easily.

3. MWT allows me to communicate with my lecturers easily.

4. MWT allows me to collaborate in group assignments with my classmates efficiently.

5. Overall, MWT is a useful tool in my studies.

\section{Ease of use}

1. It is easy to learn on how to use MWT.

2. I frequently use MWT in my daily life.

3. Mobile chat/text messaging applications are easy to use.

4. Using MWT requires very little mental effort.

5. $\quad$ Overall, I find MWT easy to use.

\section{Self-efficacy}

1. I have the skill/knowledge to use MWT

2. I do not need to consult the user manual when using MWT.

3. I can communicate with my classmates comfortably using MWT.

4. I can communicate with my lecturers comfortably using MWT.

5. Overall, I am confident in using MWT.

\section{Enjoyment}

1. I like using MWT to communicate with friends and family.

2. Sharing message, pictures, videos, etc. online using MWT is fun.

3. I enjoy playing games on my mobile devices.

4. It is fun to surf the Internet using MWT.

5. Overall, I enjoy using MWT.

\section{Uncertainty avoidance}

1. I do not find it troublesome to use new mobile devices/applications.

2. I am willing to try use a mobile device/application even if overall reviews are not good.

3. I frequently download mobile applications.

4. I enjoy trying out new mobile applications.

5. Overall, I tend to use new MWT to look for new updates/tools/applications.

\section{System quality}

1. I rarely encounter system errors when using mobile devices/applications.

2. It is easy to recover from errors encountered when using mobile 
devices/applications.

3. I find it easy to get mobile applications to do what I want it to do.

4. Mobile chat application(s) which I am using has very good features.

5. Overall, quality of mobile applications' functionalities is very important.

\section{Information quality}

1. My mobile devices' operating system allows me to customize the way I prefer my data to be presented.

2. I have no problem understanding mobile applications' instructions.

3. My mobile operating system interface layout is attractive.

4. My mobile operating system generates output (data) that is easy for me to understand.

5. $\quad$ Overall, quality of data output generated by mobile applications is important.

\section{MWT adoption intention}

1. I prefer to ask questions during lecture by typing and sending the questions using mobile messaging application to my lecturer mobile device.

2. I prefer to respond to my lecturer questions during lecture by typing and sending the answers using mobile messaging application to my lecturer mobile device.

3. My lecturer should allow and encourage us to send or answer questions during lectures using mobile messaging application.

4. My university/college should promote the use of MWT to allow students and lecturers to communicate during lectures.

5. Overall, I prefer to use MWT to communicate with my lecturer during lecture sessions.

\section{Athabasca \\ University}

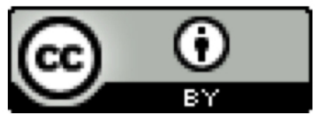

